\title{
Controversies in Orthopaedic Trauma- Management of Fractures of Shaft of Femur in Children Between 6 and 12 Years of Age
}

\author{
Jain $A,{ }^{1}$ Aggarwal $A,{ }^{1}$ Gulati $D,{ }^{2}$ Singh $\mathrm{MP}^{1}$
}

\author{
${ }^{1}$ Department of Orthopaedics \\ UCMS and Assoc. GTB Hospital \\ Dilshad Garden \\ ${ }^{2}$ Fortis Hospital \\ Delhi, India

\section{Corresponding Author} \\ Anuj Jain \\ Department of Orthopaedics \\ UCMS and Assoc. GTB Hospital \\ Dilshad Garden \\ Delhi, India \\ E-mail: jain.doctor.anuj@gmail.com
}

\section{Citation}

Jain A, Aggarwal A, Gulati D, Singh MP. Controversies in Orthopaedic Trauma- Management of Fractures of Shaft of Femur in Children Between 6 and 12 Years of Age. Kathmandu Univ Med J 2014;45(1):77-84.

\begin{abstract}
The management of femoral shaft fractures in children is largely directed by the age and built of the child. There is wide consensus on the non operative treatment of children less than six years of age. Operative treatment is recommended for children more than 12 years of age, only the surgical options vary. The age group of 6-12 years remains a controversial area with multiple studies advocating different lines of treatment.

We studied the literature on treatment of femoral shaft fractures in 6 to 12 year age group over the past 25 years through PubMed search and found 79 studies dealing with management of paediatric shaft femur fractures in this age group. Studies dealing with other age groups, animal studies and languages other than English were excluded. The treatment modalities included early or immediate hip spica, traction alone, external fixator, plating (open/minimally invasive), intramedullary nailing- rigid/flexible and intramedullary Kirschner wire. The short listed articles were studied for rate and time of union, complications such as non-union and malunion, leg length discrepancy, infection, implant impingement, refracture and cost analysis.
\end{abstract}

Operative treatment is usually the preferred treatment option in this age group, as it decreases hospitalization time, decreases morbidity and allows early return of child to school. Flexible intramedullary nailing is recommended for length stable fractures. Submuscular bridge plating (minimally invasive) is reserved for comminuted fractures. External fixator is reserved for open fractures and initial stabilization of femoral shaft fractures in polytrauma pediatric patients. Intramedullary $\mathrm{K}$ wire is a viable option in resource contrained centres where specialized implants and instrumentation is not available.

\section{KEYWORDS}

Children, femur, fracture, paediatric, shaft

\section{INTRODUCTION}

Most paediatric femoral shaft fractures unite rapidly regardless of the fracture type, location and treatment given. However suboptimal outcomes in the form of malunion, delayed union, limb length discrepancy and growth disturbances are known. Therefore the management of femoral shaft fractures in children is largely directed by the age, fracture pattern, associated injuries and social and economic situation of the child and family. As the treatment methods have evolved, the trend has been moving away from non operative methods such as traction and spica casting towards operative methods such as external fixation, open/minimally invasive plating, and flexible/rigid intramedullary nailing. Each method has its set of advantages and disadvantages.

There is a broad consensus on the non operative treatment of paediatric femoral shaft fractures, in the form of spica casting with or without initial traction, in children less than six years of age. Operative treatment, usually in the form of rigid intramedullary nailing or plating is recommended 
for children more than 12 years of age. The age group of 6-12 years remains a controversial area with multiple studies advocating different lines of treatment ranging from immediate spica casting to rigid intramedullary nail fixation.

\section{METHOD}

A 'PubMed' search was conducted with the key words 'shaft', 'femur', 'fracture', 'children', with articles from January 1987 to January 2012. A total of 162 results in English language were obtained in last 25 years. Of these 79 were relevant to the management of fracture of shaft femur in the age group of 6-12 years. Studies dealing with other age groups, animal studies and languages other than English were excluded. A number of studies were found spanning multiple age groups including the age group in question. Only those studies were considered in which the mean age was between 6-12 years or where data specific to this age group was extractable from the article text. The short listed articles were studied for treatment modality, rate and time of union, complications such as non-union and malunion, leg length discrepancy (LLD), infection, implant impingement, refracture, need for repeat surgery and cost analysis.

\section{Nonoperative Methods (spica, traction and functional bracing)}

Infante et al reviewed 175 children (42 patients were between 7 to 11 years) with femoral shaft fracture treated by immediate close reduction and hip spica cast with at least two years follow up. All fractures united in eight weeks. The only complication was a refracture. The authors concluded that immediate closed reduction and well moulded spica cast application is a safe and reliable treatment option for isolated closed femoral shaft fractures from birth to ten years and in patients weighing less than 80 pounds. ${ }^{1}$ Sugi $\mathrm{M}$ et al concluded that in children ten years or younger and without any other injury early spica casting is a simple and effective method of treatment. ${ }^{2}$ In another study, 20 children between 5- 12 years were evaluated by plain radiograph (for angular alignment) and CT scans (for rotational malalignment). The mean sagittal angualtion was 17 degrees and mean coronal plane angulation was nine degrees. The mean rotational malunion was 9.5 degrees. Thirty percent cases had rotational malunion of more than 20 degrees. However no correlation was found with type and level of fracture and the deformity. ${ }^{3}$ In a similar study 28 children with femoral shaft fractures treated with early spica cast were evaluated with CT scan for rotational deformities. Internal rotation deformity was detected in nine cases and external rotation deformity was detected in 17 cases. In 4 out of 28 cases, the rotational deformity was of more than ten degrees and required correction by gypsotomy. ${ }^{4}$ A prospective study of 101 femoral fractures, with children aged ten years and younger, concluded that only four spica casts required removal at 7- 10 days for unacceptable shortening (more than two cms). ${ }^{5}$ A study comprising of 110 patients studied the incidence and contributing factor associated with post casting peroneal nerve palsy. Four patients with peroneal nerve palsies were identified. All four had 90-90 cast and underwent cast wedging for realignment. All palsies resolved with immediate spica removal. ${ }^{6}$ A prospective study of 38 children (mean age of 6.5 yrs) treated with close reduction and early spica casting with incorporation of supracondylar kirschner wires observed that at mean follow up of 65.6 months (range, 58-80 months), no child had any residual skeletal deformity and joint stiffness. The maximal shortening was $11 \mathrm{~mm}$ and overgrowth was 6 $\mathrm{mm}$. The authors concluded that the only factor associated with unacceptable shortening $(>15 \mathrm{~mm})$ was shortening of more than $15 \mathrm{~mm}$ at time of spica application. ${ }^{7}$

The role of traction is not well defined in literature. Valanghiman et al concluded that skeletal traction provides no benefit in comparison to skin traction while waiting for definite fixation. ${ }^{8}$ Song et al reported a study of comparison between nonoperative treatment and retrograde flexible nailing in paediatric femoral shaft fractures. Fifty-one femoral fractures (24 nonoperative and 27 nailing) in 46 patients were studied retrospectively. Four cases of angular deformity (greater than ten degrees) were observed from the nonoperative treatment group and none from the nailing group. Nonoperative treatment showed a wider variance of limb length discrepancy and four cases showed severe LLD of more than one $\mathrm{cm}$ while the nailing group had no LLD. ${ }^{8}$ According to Flynn et al children treated with titanium elastic nails when compared with children treated with traction and cast, had shorter hospitalization time, walked with support earlier, walked independently earlier and returned to school earlier. ${ }^{10}$ In a series of 96 femoral fracture patients Reeves et al compared results of traction and subsequent casting with rigid internal fixation. They concluded that operative management decreased hospitalization, which had psychological, educational and economic advantages over nonoperative management. ${ }^{11}$ In another method, 30 children were treated with short period of traction followed by full weight bearing with a modified hinged brace. The children returned to school after an average of 32.5 days. At two years, no child had shortening, residual angulation or rotational deformities greater than 10 and 15 degrees respectively. Overgrowth of the fractured femur was common. No strong correlation was found between overgrowth and age, site, and type of fracture. ${ }^{12}$

According to the available literature, the major disadvantages of spica casting are the result of prolonged immobilization or inability to control reduction in certain situations as large or obese patients. It restricts access to soft tissues and mobilization and positioning in polytrauma patients. Otherwise spica casting is a simple, safe and effective method of treatment and avoids surgery and generally requires no special tools and implants. This 
method has been found suitable for younger children as they have tremendous ability to remodel the deformities.

\section{External Fixator}

Kapukaya et al reported encouraging results with the use of external fixator in closed fracture shaft femur. They did not find any case of LLD or malunion in their series of 57 patients and reported just three cases of infection and one refracture. ${ }^{13}$ Davis et al treated 15 paediatric femoral fractures all of which healed without additional operative intervention. They concluded that external fixation is also an effective means of treating isolated femoral fractures in the paediatric population. ${ }^{14}$ Hedin et al recommended fixing femoral shaft fracture without shortening regardless of the age of the child, type of fracture, fracture level. They concluded that the recommendation to allow displaced femoral fracture in children less than 12 years to heal with shortening to compensate for subsequent overgrowth is not applicable when using external fixator. ${ }^{15}$ Sola et al concluded that use of an auxillary pin reduced the rate of malunion. ${ }^{16}$ Domb et al, in a study comparing static and dynamic external fixation, concluded that dynamization had no significant effect on time to healing or frequency of complications. ${ }^{17}$ A retrospective study of 27 pediatric patients with femoral shaft fractures treated by external fixation evaluated the complications and outcomes. There were eight major complications in six patients and 29 minor complications in 20 patients. The major complications included two refractures, two fractures through pin sites, one supracondylar femoral fracture, one persistent pin-tract infection requiring early fixator removal, one malunion and one loss of reduction. Five of the eight major complications were secondary to errors in operative technique or postoperative treatment. Minor complications included pin-tract infections requiring oral antibiotics, refusal to go to school, scar and insignificant malunion. The minor complications were considered intrinsic to the procedure and difficult to avoid. ${ }^{18}$ Hedin et al found 59 cases of LLD, 35 pin tract infections and two refractures in 97 patients studied. ${ }^{15}$ Miner et al found five cases of LLD, 24 pin tract infections and eight refractures in 37 patients studied in similar age groups (4-14). ${ }^{19}$ Similar high rates of complications have been reported by Krettek and Siegmeth. ${ }^{20,21}$ Barlas et al treated 20 patients each with external fixator and flexible intramedullary nails and found significantly more complications with external fixator. ${ }^{22}$ Scannell et al concluded that external fixator in damage control for femur fractures in severely injured patients offer no significant advantage in clinical outcomes. Unless initially subjected to general anesthesia for life saving procedures, the use of skeletal traction as a temporization method remains a practical option. ${ }^{23}$

External fixator, when used after closed reduction, is minimally invasive, entailing little blood loss, and allows access to wounds and soft tissues in open injuries. It has been seen that external fixator may lead to rigid stabilization of the fracture and therefore decreasing the callus formation and delayed union. Early removal of fixator may lead to refracture. Therefore it is recommended that fixator should be kept in place until there is bridging callus across the fracture site in at least three cortices in two orthogonal views. However they are difficult to use in proximal and distal fractures due to difficulty in pin placement in the region of growth plates. The high rates of infection and refracture (ranging from 1 to $22 \%$ ) after pin removal have restricted the indications of external fixator to some grades of open fractures and for damage control in a polytraumatized patient. Moreover the fixator has to be in place for a longer duration of time till bridging callus is seen in atleast three cortices.

\section{Plating}

A retrospective review of 60 children between age 3 to 15 years ( mean age 8 years) with femoral shaft fractures treated with open reduction and compression plate fixation found $100 \%$ union rate and an overall ten percent complication rate. The authors concluded that compression plate fixation has advantage of rigid and anatomic reduction and shorter hospital stay and early mobilization of the extremity. Disadvantages include scar over the thigh, need for hardware removal, increased blood loss and risk of refracture after hardware removal. ${ }^{24}$ Similar studies by Reeves et al, Ward et al, Kregor et al and Van Niekerk have reported high union rates, and few complications with use of plates for stabilization of paediatric femoral shaft fractures in multiply injured patients. ${ }^{10,25-27}$ In a retrospective review of 40 children (46 femur fractures), aged 4 to 10 years were treated with open reduction and plate fixation. There were no nonunions. Complication included one case of osteomyelitis and one refracture. They observed limblength discrepancy averaging $1.2 \mathrm{~cm}$ (range $0.4-1.8 \mathrm{~cm}) .^{28} \mathrm{~A}$ study on 15 femoral shaft fractures with multiple injuries or a head injury, managed with compression plating concluded that plate fixation of the femur is a good treatment option for children who have a femoral shaft fracture associated with major head injury or multiple injuries, or both. ${ }^{26}$ Skak et al compared open plating (17 patients) with flexible (10 patients) and rigid intramedullary nails (25 patients) in the age group of 6 to 17 years. The authors did not report any complication with the use of plate and two malunions with each kind of nailing, one AVN after rigid nailing and heterotrophic ossification in all cases of rigid nailing. ${ }^{29}$ Fyodorov et al reviewed 21 patients (8-12 years) in whom $4.5 \mathrm{~mm}$ dynamic compression plates (DCP) were used for fixation. Hardware failure occurred in two patients at six weeks. One was treated with revision plating, and the other, with spica casting. Both healed uneventfully and no other complications occurred. ${ }^{30}$ Hammad et al studied 15 patients treated by DCP in locking mode and found one case of malunion, six cases of LLD and three cases of implant failure. ${ }^{31}$

Most complications of open reduction and plating have been reported due to extensive surgical exposure and periosteal stripping. Twenty seven patients underwent submuscular 
bridge plating for unstable pediatric femoral fractures. Early callus formation was seen by six to eight weeks and stable bony union was achieved by 12 weeks in all patients. The authors concluded that submuscular plating is a reasonable option for operative stabilization of comminuted and unstable pediatric femoral fractures. ${ }^{32}$ In another study on submascular bridge plating, fifty-one patients with an average age of ten years were studied with average follow up of 14.2 months. All fractures united and average time for bridging of four cortices was 14 weeks. Thirty Six out of 51 patients underwent hardware removal at end of eight months. Significant complications included fracture of one 3.5-mm limited contact dynamic compression plate and one refracture of a pathologic fracture after early plate removal. Four patients had a leg-length discrepancy ranging from $23-\mathrm{mm}$ shortening to $10-\mathrm{mm}$ lengthening. They reported no rotational malalignment. ${ }^{33}$ In another study fourteen children with mean age of 11.3 years with closed comminuted femur shaft fracture were treated by biologic internal fixation using a bridging plate. Average union time was 12.4 weeks. The authors conclude that plating provides excellent stability and allows management of proximal and distal fractures that are not suitable for nailing or external fixation. ${ }^{34}$ Caglar et al compared 21 patients treated with minimally invasive plating with 17 patients treated by titanium elastic nail system (TENS) in the age group 6-12 years and did not find any difference in healing time but found fewer complications with plate. ${ }^{35}$

Plating provides excellent stability and allows management of fractures of proximal and distal femur that are not suitable for nailing or external fixation. However open reduction and plating can involve significant blood loss during application and during implant removal. In addition second extensive surgery is required for hardware removal. Overall, plating for pediatric shaft femur fractures has shown mixed results. Minimally invasive plating (submuscular bridge plating) holds promise but it has a learning curve.

\section{Rigid Intramedullary Nailing}

In pediatric patients, intramedullary rigid nail fixation may result in injury to growth plate and avascular necrosis of femoral head. Raney et al reported premature epiphysiodesis of greater trochanteric apophysis in five of his patients secondary to intramedullary femoral nailing and didn't recommend this procedure in children less than 12 years. ${ }^{36}$ Letts et al reported a study on complications of rigid intramedullary nailing of femoral shaft fractures in children. They observed minor limb length discrepancy in eight cases, discomfort because of nail prominence in eleven cases, avascular necrosis of the femoral head in one case, broken nail in one case and deep infection in one case. ${ }^{37}$ O'Malley et al reported avascular necrosis of femoral head associated with intramedullary nailing in an adolescent. They hypothesized that injury to posterior superior ascending branch of the medial circumflex artery at the time of nail insertion may have led to this complication. This artery is situated close to proximal insertion hole just posterior to the trochanteric notch and piriformis fossa. They concluded that in children with open femoral physes, rigid nailing should be avoided because of small but serious occurrence of avascular necrosis of the femoral head. ${ }^{38}$

To offset the complication of AVN by a piriformis fossa entry point, a lateral greater trochanter entry point was used in few studies. ${ }^{39,40}$ No AVN was seen but growth disturbance due to physeal arrest of trochanteric physis was a concern. ${ }^{41,42}$ Gonzales-Herranz et al studied the effects of femoral intramedullary nailing in 34 children and reported $30 \%$ incidence of abnormality at the proximal end of femur including valgus, arrest of the greater trochanter apophysis, and thinning of the neck of femur. ${ }^{41}$ Gordon on the other hand did not find any proximal femur abnormalities with intramedullary nailing of femoral fractures in 25 children through the lateral aspect of the greater trochanter using a modified rigid humeral intramedullary nail. ${ }^{39}$ Though fairly good results are observed in the form of less number of malunions and LLD, various authors reserve the use of rigid intramedullary devices beyond 12 years of age or $49 \mathrm{~kg}$ of weight. ${ }^{43}$

\section{Flexible Intramedullary Nailing}

Ender's nailing

Ender's nailing has been used as a less expensive alternative to Titanium nails in less developed countries. The principle of fixation differs from TENS as Ender's nails have to be stacked in the medullary canal to improve canal fill and achieve stability instead of providing three point fixation by balancing opposing forces of two deformed TENS nails. Ozdemir et al reported a retrospective study on percutaneous Ender's nail fixation and functional bracing for the treatment of 53 paediatric femoral shaft fractures in the age group 6-14 years. There were no significant intra or postoperative complications. The main advantages of this method are early weight bearing, immediate mobilization, short hospitalization and fewer complications. ${ }^{44}$ Similar results were reported by Cramer et al (57 patients, 5-14 yrs, four cases of malunion, no LLD) and Timmerman et al(29 patients, $10-12 \mathrm{yrs}, 4$ LLD, no malunion). ${ }^{45,46} \mathrm{Kissel}$ and Miller reported a study of 28 patients ranging from 8-13 years old, who were treated for diaphyseal femur fractures. Fourteen patients were treated by conventional 90-90 balanced skeletal traction with late spica cast application and 14 were treated with closed retrograde Ender nailing. They observed that closed Ender's nailing yield results superior to conventional method of treatment with the advantage of early discharge from the hospital and return to school. ${ }^{47}$ Ellis et al concluded that locked Enders nail for unstable fractures is a good option to prevent shortening with no additional complication as compared to non locked Ender's nail. ${ }^{48}$ Khazzam et al reported comparison of results of treatment with Ender's nailing (72 patients) and TENS (66 patients) and found lesser complications like malunion, implant impingement and refracture with use of TENS. ${ }^{49}$ Kumar et al found no significant difference in result 
in children treated by TENS and Enders nail. ${ }^{50}$ Ligier et al stated that "Ender nails are not elastic enough for treating children" and reported excellent results with titanium elastic nails. Extensive experience with Ender's nails reveals problems with lack of rotational control, inability to prevent longitudinal collapse in unstable fracture patterns and backing out of implants. ${ }^{51}$

\section{ESIN (Elastic Stable Intramedullary Nailing)}

Elastic Stable Intramedullary Nailing (ESIN) is a biological, minimally invasive fracture treatment modality to achieve a level of reduction and stablization that is appropriate to the age of the child. Barry and Paterson and Flynn et al recommended titanium elastic nails to be the ideal implant to stabilize many paediatric femur fractures, avoiding prolonged immobilization and complications of traction and spica casting. ${ }^{52,53}$ They postulated that nonunion or delayed union is uncommon and when it occurs, it may be related to the use of nails of inadequate diameter. Growth disturbance appears to be minimal due to avoidance of proximal and distal physes with a mean femoral overgrowth of only $1.2 \mathrm{~mm}$. A retrospective review of antegrade flexible intramedullary nailing in 25 femoral shaft fractures concluded that flexible intramedullary nailing is a safe and effective method for the treatment of femoral shaft fractures in the child between 6 and 12 years of age. ${ }^{54}$ Aktekin et al reported a study on flexible intramedullary nailing in 21 patients in the age group 6-12 years with diaphyseal fractures of femur, treated with titanium elastic nailing. There was no angular or rotational deformity at one year follow up. They recommended flexible titanium nailing as the first treatment choice in this age group. ${ }^{55}$ Singh et al conducted a study on titanium elastic nailing in paediatric femoral diaphyseal fractures on 35 patients (age group 6-14 years). The results were excellent in twenty five, satisfactory in eight and poor in two patients. All the fractures healed with an average time to union of 9.6 weeks. Return to school was early with an average of 7.8 weeks. The most common problem encountered was pain and discomfort near the knee produced by the nail ends. Three cases had shortening and restriction of knee flexion was observed in five patients. There was no delayed union, infection or re-fractures. ${ }^{56}$ Bar-On et al reported outcome of femoral shaft fractures in children of age group 5-13 years requiring surgery randomly treated with external fixator or flexible intramedullary nailing (10 patients each). They recommend flexible intramedullary nailing for fractures of the femoral shaft and reserved external fixation for open or severely comminuted fractures. ${ }^{57}$ In another study, paediatric femoral shaft fractures treated with flexible titanium nails over a four year period were reviewed. Of the 70 fractures reviewed, malunion occurred in 16 fractures, of which 11 had increased anterior bow. The authors concluded that anterior bow deformity can be prevented if at least one of the nails is inserted with the tip pointing in an anterior direction to counter the procurvatum. They also noted that most malunions occurred in transverse fracture patterns and weight of the patient was determined to be significant predictor of anterior bow deformity. ${ }^{58} \mathrm{Li}$ ea al provided biomechanical evidence that patients weighing more than 40 to $45 \mathrm{~kg}$ who undergo stabilization of a transverse midshaft femur fracture with titanium elastic nails are at risk for loss of reduction in the sagittal and coronal planes. ${ }^{59}$ Luhmann et al found no correlation between weight and coronal and sagittal angulation. There was no significant relation between weight nail ratio and coronal angulation ( $p=0.4237$ ) while sagittal angulation increased with increased weight nail ratio $(p=0.0007) .{ }^{60}$ Salem et al concluded elastic stable intramedullary nailing with six month (4-7 month) follow up can provide satisfactory results in terms of limb length and axial alignment, but has a high rate of early torsional malalignment (47\%). ${ }^{61}$ In a study, 36 children with 37 closed fractures were treated by flexible intramedullary nailing. Follow-up radiographs revealed that $44 \%$ of the children had malalignment at the fracture site in one or both planes. However none of the children presented with clinical malalignment of the fractured limb. Fifty percent of the children had a leg-length inequality but none of them complained of a functional problem. ${ }^{62}$ Houshian et al reported a series of 31 children (4-11 years) with femoral shaft fractures treated with ESIN. All fractures radiographically united at a median of seven weeks. Limb length discrepancy of up to one $\mathrm{cm}$ was found in six children and ten degrees of rotational deformity in one child and no case of angular deformity. ${ }^{63}$ In a multicentric study of TENS, Flynn et al reported excellent or satisfactory results in 57 of 58 patients with six patients having LLD, four cases of nail impingement and one refracture after implant removal. ${ }^{64}$ Luhmann et al retrospectively reviewed 43 shaft femur fractures and found $49 \%$ complication rate but only two major complications (one non-union and one deep infection). The most common minor complication was pain at the nail insertion site. ${ }^{60}$ Narayanan et al reported a study on complications of ESIN in 79 paediatric femoral fractures. Complications included pain and irritation at the nail insertion site in 41 cases, radiographic mal-union in eight cases, refractures in two cases, transient neurologic deficit in two cases and superficial wound infection in two cases. Ten patients required re operation prior to union. Three patients had nail migration and skin perforation, three patients had loss of reduction, two patients had re fracture and one patient had neural deficit. Mal-union and loss of reduction requiring re operation were strongly associated with the use of nails of mismatched diameter and comminution of more than $25 \% .{ }^{65}$ Sink et al conducted a study to analyze the complications in 39 children with femur fractures stabilized with titanium elastic nails and concluded that in patients with length unstable femur fractures, consideration should be given to methods of treatment other than titanium flexible intramedullary nails. ${ }^{66}$ Ann Ho et al reported a study on use of flexible intramedullary nails in 94 paediatric femur fractures. The complication rate was significantly higher for patients aged ten years or older compared to younger patients. ${ }^{67}$ Similar 
results were also reported by Moroz et al. ${ }^{43}$

In a retrospective analysis of 53 femoral and 24 tibial shaft fractures, the use of image intensifier at several steps of the operative procedure was evaluated. It was seen that the most intense use of imaging was during fracture passage (43.2\%) and placement of the nail tips (26.6\%). The average radiation time in femoral fractures was 70.3 (range, 12-193 sec.)..$^{68}$

In a study aimed to compare the mechanical properties of different nail combinations by testing them in a model of a child's midshaft femoral fracture, two C-shaped nails were compared with two straight nails and with paired $\mathrm{S}$ - and C-shaped nailsructs. The authors concluded that any of the tested nail combinations can be used to treat a midshaft fracture of the femur in a child. ${ }^{69} \mathrm{~A}$ finite element model of a femur with complete mid-diaphyseal fracture and having two $3.5 \mathrm{~mm}$ nails in a retrograde " $\mathrm{C}$ " pattern was created. Static analyses were run in which the nail material properties were titanium alloy or stainless steel, respectively. They reported increased gap closure and nail slippage with stainless steel nails and increased stability with titanium nails. Additionally, stainless steel nails could hamper remodeling and consequently increase risk of refracture. ${ }^{70}$ On the contrary Wall et al comparing stainless steel and Titanium elastic nails for fixation of paediatric shaft femur fractures (mean age- 9.4 years) found that the less expensive stainless steel nails are superior to titanium nails owing to a lesser rate of malunion (6.3\% vs. $23.2 \%) .{ }^{71}$

Flexible intramedullary nailing offers several advantages including a better reduction, dynamic stabilization, and short hospital stay with early functional recovery, lower treatment costs and a simplified implant removal. The technique is usually closed and minimally invasive. The minimal operative trauma, the undisturbed periosteal and endosteal vasculature and nail elasticity favours rapid fracture union in the paediatric age group. But the uncertain control of rotation, difficulty in fixation of more proximal and distal fractures, maintenance of length in comminuted and unstable fracture pattern, frequent impingement of implant and requirement of another procedure for implant removal are some of the disadvantages of this procedure. It is preferable to use these implants till 12 years of age in length stable mid shaft femoral fractures due to the results of recent studies favouring plate over elastic nails in closed comminuted fractures of shaft and for fractures that are more distal or proximal in location.

\section{Intramedullary Kirschner Wire}

Jawadi et al reported 184 cases (4-14 years) with a one year follow-up and found just three cases of LLD and implant impingement, and one case of infection. No case of malunion or delayed union was reported. ${ }^{72}$ Similar good results were also reported by Chitgopkar (17 patients) and Matsubara (19 patients). ${ }^{73,74}$ On the other hand, Qidwai et al reported 10 cases of LLD in their series of 53 patients. There were no malunion or loss of reduction. ${ }^{75}$ Most of the study used two K- wires $2.5 \mathrm{~mm}$ - 3. $5 \mathrm{~mm}$ diameter of variable lengths. Usually no additional support was used except patients with additional injuries. Weight bearing was restricted till evidence of callus was seen on radiograph.

The studies using intramedullary $\mathrm{K}$ wire have predominantly originated from less developed countries and are as good as results of other widely accepted operative methods of treatment as plating and flexible intramedullary nailing, although the number of studies is small. It provides a reasonable option for treatment in areas where material and financial resources are constrained.

\section{Cost Analysis}

Stans et al reported a study to evaluate the morbidity cost of various methods used for treatment of 85 femoral shaft fractures in patients of the age group 6-16 years. Patients were treated by methods like early spica casting; traction followed by spica casting, external fixation, compression plating, and flexible intramedullary nailing and reamed nailing. They observed that early spica casting gave excellent results with low complication and low cost and is the best method when feasible. All surgical treatments cost approximately three times the cost of early spica casting and equivalent to traction followed by spica casting. ${ }^{42}$ Other study also directly correlates cost of treatment with duration of stay in hospital. Hedin et al concluded that main factor for determining the cost of treatment was the number of days in hospital. ${ }^{15}$ Gaid et al concluded operative treatment reduced the inpatient stay by approximately $75 \%$ and thereby reducing the overall cost for treatment by $60 \%$ in comparison to traction alone and by almost $30 \%$ in comparison to using traction followed by casting. ${ }^{76}$ Coyte et al and Nork et al concluded that the total cost of treatment by external fixator were greater than hip spica group but less than skeletal traction followed by spica group. ${ }^{77,78}$

\section{CONCLUSION}

The ideal device for the treatment of most femoral fractures in children should be a simple, load sharing internal splint that allows mobilization and maintenance of alignment and limb length until bridging callus forms. The implant should neither endanger the physis nor the blood supply to the femoral head. It should promote, rapid healing and should provide for ability to remodel.

The literature recommends flexible intramedullary nailing in this age group for length stable fractures. Submuscular bridge plating (minimally invasive) is reserved for comminuted fractures. External fixator is reserved for open fractures and initial stabilization of femoral shaft fractures in polytrauma pediatric patients. Intramedullary $\mathrm{K}$ wire is a viable option in resource contrained centres where specialized implants and instrumentation is not available. Nonoperative treatment is now a less preferred option owing to increased morbidity and higher costs involved if the entire treatment is supervised in hospital. Reamed 
nailing is reserved for patients older than 12 years and nearing skeletal maturity. However, the indication of type of implant to be used in this age group (6-12 years) depends upon an individual surgeon's experience and availability of resources. $^{79}$

\section{REFERENCES}

1. Infante AF Jr, Albert MC, Jennings WB. Immediate hip spica casting for femur fractures in pediatric patients. A review of 175 patients. Clin Orthop Relat Res. 2000; 376: 106-12.

2. Sugi M, Cole WG. Early plaster treatment for fractures of the femoral shaft in childhood. J Bone Joint Surg Br. 1987 Nov;69(5):743-5.

3. Puttaswamaiah $R$, Chandran $P$, Sen R. Deformities in conservatively treated closed fractures of the shaft of the femur in children. Acta Orthop Belg. 2006; 72(2): 147-53.

4. Bulut $\mathrm{S}$, Bulut $\mathrm{O}$, Taş $\mathrm{F}$, Eğilmez $\mathrm{H}$. The measurement of the rotational deformities with computed tomography in femoral shaft fractures of the children treated with early spica cast. Eur J Radiol. 2003 Jul;47(1):38-42.

5. Ferguson J, Nicol RO. Early spica treatment of pediatric femoral shaft fractures. J Pediatr Orthop. 2000; 20(2): 189-92.

6. Weiss AP, Schenck RC Jr, Sponseller PD, Thompson JD. Peroneal nerve palsy after early cast application for femoral fractures in children. $J$ Pediatr Orthop. 1992 Jan;12(1):25-8.

7. Sahin V, Baktir A, Türk CY, Karakaş ES, Aktaş S. Femoral shaft fractures in children treated by closed reduction and early spica cast with incorporated supracondylar Kirschner wires: a long-term follow-up results. Injury. 1999 Mar;30(2):121-8.

8. Vanlaningham CJ, Schaller TM, Wise C. Skeletal versus skin traction before definitive management of pediatric femur fractures: a comparison of patient narcotic requirements. J Pediatr Orthop. 2009 Sep;29(6):609-11.

9. Song $H R$, Oh $C W$, Shin HD. Treatment of femoral shaft fractures in young children: comparison between conservative treatment and retrograde flexible nailing. J Pediatr Orthop B. 2004; 13(4): 275-80.

10. Flynn JM, Luedtke LM, Ganley TJ. Comparison of titanium elastic nails with traction and a spica cast to treat femoral fractures in children. $J$ Bone Joint Surg Am. 2004; 86: 770-7.

11. Reeves RB, Ballard RI, Hughes JL. Internal fixation versus traction and casting of adolescent femoral shaft fractures. J Pediatr Orthop. 1990; 10: 592-5.

12. Cheng JC, Cheung SS. Modified functional bracing in the ambulatory treatment of femoral shaft fractures in children. J Pediatr Orthop. 1989 Jul-Aug;9(4):457-62.

13. Kapukaya A, Subasi M, Necmioglu S. Treatment of closed femoral diaphyseal fractures with external fixators in children. Arch Orthop Trauma Surg. 1998; 117(6-7): 387-9.

14. Davis TJ, Topping RE, Blanco JS. External fixation of pediatric femoral fractures. Clin Orthop. 1995; 318: 191-8.

15. Hedin H, Hjorth K, Larsson S, Nilsson S. Radiological outcome after external fixation of 97 femoral shaft fractures in children. Injury. 2003 May;34(4):287-92.

16. Sola J, Schoenecker PL, Gordon JE. External fixation of femoral shaft fractures in children: enhanced stability with the use of an auxiliary pin. J Pediatr Orthop. 1999 Sep-Oct;19(5):587-91.

17. Domb BG, Sponseller PD, Ain M, Miller NH. Comparison of dynamic versus static external fixation for pediatric femur fractures. J Pediatr Orthop. 2002 Jul-Aug;22(4):428-30.

18. Gregory P, Pevny T, Teague D. Early complications with external fixation of pediatric femoral shaft fractures. J Orthop Trauma. 1996;10(3):191-8.

19. Miner T, Carroll KL. Outcomes of external fixation of pediatric femoral shaft fractures. J Pediatr Orthop. 2000; 20(3): 405-10.
20. Krettek C, Haas N, Walker J. Treatment of femoral shaft fractures in children by external fixation. Injury. 1991; 22(4): 263-6.

21. Siegmeth A, Wruhs O, Vecsei V. External fixation of lower limb fractures in children. Eur J Pediatr Surg. 1998; 8(1): 35-41.

22. Barlas $\mathrm{K}$, Beg $\mathrm{H}$. Flexible intramedullary nailing versus external fixation of paediatric femoral fractures. Acta Orthop Belg. 2006; 72(2): 15963.

23. Scannell BP, Waldrop NE, Sasser HC, Sing RF, Bosse MJ. Skeletal traction versus external fixation in the initial temporization of femoral shaft fractures in severely injured patients. J Trauma. 2010 Mar;68(3):633-40.

24. Caird MS, Mueller KA, Puryear A, Farley FA. Compression plating of pediatric femoral shaft fractures. J Pediatr Orthop. 2003 JulAug;23(4):448-52.

25. Ward WT, Levy J, Kaye A: Compression plating for child and adolescent femur fractures. J Pediatr Orthop. 1992; 12: 626-32.

26. Kregor PJ, Song KM, Routt MIC Jr. Plate fixation of femoral shaft fractures in multiply injured children. J Bone Joint Surg Am. 1993; 75: 1774-80.

27. Van Niekerk JL, Dooren DP, Klasen HJ, Binnendijk B. Indications and results of osteosynthesis by plate fixation of femoral shaft fractures in children. Neth J Surg. 1987 Aug;39(4):129-31.

28. Eren OT, Kucukkaya M, Kockesen C. Open reduction and plate fixation of femoral shaft fractures in children aged 4 to 10. J Pediatr Orthop 2003; 23(2): 190-3.

29. Skak SV, Overgaard S, Nielsen JD. Internal fixation of femoral shaft fractures in children and adolescents: a ten-to twenty-one-year follow-up of 52 fractures. J Pediatr Orthop B. 1996; 5(3): 195-9.

30. Fyodorov I, Sturm PF, Robertson WW Jr. Compression-plate fixation of femoral shaft fractures in children aged 8 to 12 years. J Pediatr Orthop 1999; 19(5): 578-81.

31. Hammad A. Locking plate construct for femoral shaft fractures in skeletally immature patients. Acta Orthop Belg. 2008; 74(5): 630-5.

32. Sink E, Hedequist D, Morgan S, Hresko T. Results and technique of unstable pediatric femoral fractures treated with submuscular bridge plating. J Pediatr Orthop. 2006; 26: 177-81.

33. Kanlic EM, Anglen JO, Smith DG. Advantages of submuscular bridge plating for complex pediatric femur fractures. Clin Orthop Relat Res 2004; 426: 244-51.

34. Aguş $\mathrm{H}$, Kalenderer O, Eryanilmaz G. Biological internal fixation of comminuted femur shaft fractures by bridge plating in children. $J$ Pediatr Orthop. 2003; 23(2): 184-9.

35. Caglar O, Aksoy MC, Yazici M. Comparison of compression plate and flexible intramedullary nail fixation in pediatric femoral shaft fractures. J Pediatr Orthop B. 2006; 15(3): 210-4.

36. Raney EM, Ogden JA, Grogan DP. Premature greater trochanteric epiphysiodesis secondary to intramedullary femoral rodding. J Pediatr Orthop. 1993; 13: 516-20.

37. Letts M, Jarvis J, Lawton L, Davidson D: Complications of rigid intramedullary rodding of femoral shaft fractures in children. $J$ Trauma. 2002; 52: 504-6.

38. O'Malley DE, Mazur JM, Cummings RJ. Femoral head avascular necrosis associated with intramedullary nailing in an adolescent. J Pediatr Orthop. 1995; 15: 21-3. 
39. Gordon JE, Khanna N, Luhmann SJ. Intramedullary nailing of femoral fractures in children through the lateral aspect of the greater trochanter using a modified rigid humeral intramedullary nail: preliminary results of a new technique in 15 children. $J$ Orthop Trauma. 2004; 18(7): 416-22.

40. Keeler KA, Dart B, Luhmann SJ. Antegrade intramedullary nailing of pediatric femoral fractures using an interlocking pediatric femoral nail and a lateral trochanteric entry point. J Pediatr Orthop. 2009; 29(4): 345-51.

41. Gonzalez-Herranz P, Burgo-Flores J, Rapariz JM, et al. Intramedullary nailing of the femur in children; effects on its proximal end. $J$ Bone Joint Surg Br. 1995; 77: 262-6.

42. Stans AA, Morrissy RT, Renwick SE. Femoral shaft fracture treatment in patients age 6 to 16 years. J Pediatr Orthop. 1999; 19(2): 222-8.

43. Moroz LA, Launay F, Kocher MS, Newton PO, Frick SL, Sponseller PD et.al. Titanium elastic nailing of fractures of the femur in children. Predictors of complications and poor outcome. J Bone Joint Surg Br 2006; 88(10): 1361-6.

44. Ozdemir HM, Yensel U, Senaran H. Immediate percutaneous intramedullary fixation and functional bracing for the treatment of pediatric femoral shaft fracture. J Pediatr Orthop. 2003; 23(4): 453-7.

45. Cramer KE, Tornetta P 3rd, Spero CR. Ender rod fixation of femoral shaft fractures in children. Clin Orthop Relat Res. 2000; 376: 119-23.

46. Timmerman LA, Rab GT: Intramedullary nailing of femoral shaft fractures in adolescents. J Orthop Trauma. 1993; 7: 331-7.

47. Kissel EU, Miller ME. Closed Ender nailing of femur fractures in older children. J Trauma. 1989; 29: 1585-8.

48. Ellis HB, Ho CA, Podeszwa DA, Wilson PL. A comparison of locked versus nonlocked Enders rods for length unstable pediatric femoral shaftfractures. J Pediatr Orthop. 2011 Dec;31(8):825-33.

49. Khazzam M, Tassone C, Liu XC. Use of flexible intramedullary nail fixation in treating femur fractures in children. Am J Orthop. 2009; 38(3): E49-55.

50. Kumar S, Roy SK, Jha AK, Chatterjee D, Banerjee D, Garg AK. An evaluation of flexible intramedullary nail fixation in femoral shaft fractures in paediatric age group. J Indian Med Assoc. 2011 Jun;109(6):416-7, 425.

51. Ligier JN, Metaizeau JP, Prevot J. Elastic stable intramedullary nailing of femoral shaft fractures in children. J Bone Joint Surg Br. 1998; 70: 74-7.

52. Barry M, Paterson JM. A flexible intramedullary nails for fractures in children. J Bone Joint Surg Br. 2004; 86(7): 947-53.

53. Flynn JM, Hresko T, Reynolds RA. Titanium elastic nails for pediatric femur fractures: A multicenter study of early results with analysis of complications. J Pediatr Orthop. 2001; 21: 4-8.

54. Carey TP, Galpin RD. Flexible intramedullary nail fixation of pediatric femoral fractures. Clin Orthop Relat Res. 1996; 332: 110-8.

55. Aktekin CN, Ozturk AM, Altay M, Toprak A, Ozkurt B, Tabak AY. Flexible intramedullary nailing of children. Ulus Travma Acil Cerrahi Derg 2007; 13(2): 115-21.

56. Singh R, Sharma SC, Magu NK, Singla A. Titanium elastic nailing in pediatric femoral diaphyseal fractures. Indian J Orthop. 2006; 40(1): 29-34.

57. Bar-On E, Sagiv S, Porat S. External fixation or flexible intramedullary nailing for femoral shaft fractures in children. A prospective, randomised study. J Bone Joint Surg Br. 1997; 79(6): 975-8.

58. Sagan ML, Datta JC, Olney BW, Lansford TJ, Mclff TE. Residual deformity after treatment of pediatric femur fractures with flexible titanium nails. J Pediatr Orthop. 2010 Oct-Nov;30(7):638-43.

59. Li Y, Stabile KJ, Shilt JS. Biomechanical analysis of titanium elastic nail fixation in a pediatric femur fracture model. J Pediatr Orthop. 2008 Dec;28(8):874-8.
60. Luhmann SJ, Schootman M, Schoenecker PL. Complications of titanium elastic nails for pediatric femoral shaft fractures. J Pediatr Orthop. 2003; 23(4): 443-7.

61. Salem KH, Keppler P. Limb geometry after elastic stable nailing for pediatric femoral fractures. J Bone Joint Surg Am. 2010 Jun;92(6):1409-17.

62. Anastasopoulos J, Petratos D, Konstantoulakis C, Plakogiannis C, Matsinos G. Flexible intramedullary nailing in paediatric femoral shaft fractures. Injury. 2010 Jun;41(6):578-82

63. Houshian S, Gothgen CB, Pedersen NW. Femoral shaft fractures in children: elastic stable intramedullary nailing in 31 cases. Acta Orthop Scand. 2004; 75(3): 249-51.

64. Flynn JM, Hresko T, Reynolds RA. Titanium elastic nails for pediatric femur fractures: A multicenter study of early results with analysis of complications. J Pediatr Orthop. 2001; 21: 4-8.

65. Narayanan UG, Hyman JE, Wainwright AM, Rang M, Alman BA. Complications of elastic stable intramedullary nail fixation of pediatric femoral fractures, and how to avoid them. J Pediatr Orthop. 2004; 24(4): 363-9.

66. Sink E, Gralla J, Repine M. Complications of pediatric femur fractures treated with titanium elastic nails. J Pediatr Orthop. 2005; 25: 577-80.

67. Ho CA, Skaggs DL, Tang CW, Kay RM. Use of flexible intramedullary nails in pediatric femur fractures. J Pediatr Orthop. 2006; 26(4): 497 504.

68. Kraus R, Schiefer U, Schäfer C, Meyer C, Schnettler R. Elastic stable intramedullary nailing in pediatric femur and lower leg shaft fractures: intraoperative radiation load. J Pediatr Orthop. 2008 JanFeb;28(1):14-6.

69. Kiely N. Mechanical properties of different combinations of flexible nails in a model of a pediatric femoral fracture. J Pediatr Orthop. 2002 Jul-Aug;22(4):424-7.

70. Perez A, Mahar A, Negus C, Newton P, Impelluso T. A computational evaluation of the effect of intramedullary nail material properties on the stabilization of simulated femoral shaft fractures. Med Eng Phys. 2008 Jul;30(6):755-60

71. Wall EJ, Jain V, Vora V, Mehlman CT, Crawford AH. Complications of titanium and stainless steel elastic nail fixation of pediatric femoral fractures. J Bone Joint Surg. 2008; 90(6): 1305-13.

72. Jawadi AH, Abdul-Samad A. Intramedullary Kirschner wire (K-wire) fixation of femoral fracture in children. J Child Orthop. 2007; 1(5): 277-80.

73. Chitgopkar SD. Internal fixation of femoral shaft fractures in children by intramedullary Kirschner wires (a prospective study): its significance for developing countries. BMC Surg. 2005; 5: 6.

74. Matsubara H, Yasutake $H$, Matsuda E. Treatment of femoral shaft fractures in children using intramedullary Kirschner wire pinning. J Orthop Sci. 2005; 10(2): 187-91.

75. Qidwai SA, Khattak ZK. Treatment of femoral shaft fractures in children by intramedullary Kirschner wires. J Trauma. 2000; 48(2): 256-9.

76. Gaid M, Jeer P. Cost analysis of managing paediatric femoral shaft fractures: flexible intramedullary nailing versus non-operative management. Acta Orthop Belg. 2006; 72(2): 170-5.

77. Coyte PC, Bronskill SE, Hirji ZZ. Economic evaluation of 2 treatments for pediatric femoral shaft fractures. Clin Orthop Relat Res. 1997; 336: 205-15.

78. Nork SE, Hoffinger SA. Skeletal traction versus external fixation for pediatric femoral shaft fractures: a comparison of hospital costs and charges. J Orthop Trauma. 1998; 12(8): 563-8.

79. Di Gennaro GL, Valdiserri L. Femoral shaft fractures during childhood Chir Organi Mov. 1999; 84(4): 299-307. 